\title{
An unusual case of farmer's lung in childhood
}

\author{
B. M. ANSARI \\ M.B., B.S., M.R.C.P., D.C.H. \\ The Welsh National School of Medicine, \\ University Hospital of Wales, Heath, Cardiff
}

\section{Introduction}

Farmer's lung is considered to be an extrinsic allergic alveolitis caused by the antigens found in hay moulds, of which Micropolyspora faeni is the most important in the United Kingdom. Farmer's lung occurs rarely in childhood and cases described in the literature have been mainly confined to older age groups (Rankin et al., 1962; Barrowcliff and Alabaster, 1968; Hughes et al., 1969). The following case report is of a child with farmer's lung who also had a serologically positive Paul-Bunnell reaction and antibodies to mycoplasma pneumoniae, respiratory syncitial virus (RSV), and Ebstein-Barr (EB) virus.

\section{Case report}

A child, 12 years of age, was admitted as an emergency with a month's history of non-productive cough and a 3-day history of severe progressive dyspnoea at rest and central cyanosis. The past history was non-contributory. Ampicillin had been given at home with no effect. On admission he was febrile, markedly dyspnoeic at rest with obvious central cyanosis and diffuse crepitations were heard all over the lungs. The chest X-ray showed mottled shadowing over lung fields (Fig. 1). Initial investigations shows $\mathrm{Hb}$ of $14 \mathrm{~g} / 100 \mathrm{ml}$, WBC 12,700 with a polymorphonuclear count of $53 \%$ and a slight shift to the left. The ESR was $11 \mathrm{~mm}$ in the first hour. In view of the severity of the condition treatment with cephaloridine was started with intramuscular administration for 3 days and then oral cephalexin was given for a further 3 days. The response to therapy was immediate and within 6 days clinical and radiological resolution was complete (Fig. 2). At this stage splenomegaly and a generalized lymphadenopathy was noted which slowly resolved over the next 10 days.

The possibility of farmer's lung was considered because the patient lived on a farm and had been exposed to mouldy hay. The gel diffusion test was positive and the complement fixation test showed a very high initial titre (Table 1). No atypical mononuclear cells were seen on several peripheral smears of the blood but the Paul-Bunnell test was positive.

\author{
S. H. Carter \\ M.B., Ch.B. \\ West Wales General Hospital, Carmarthen, Wales
}

FIG. 1. X-ray showing lung mottling.

The serological test for mycoplasma pneumoniae and RSV showed a four fold rise in antibody titres. The EB virus fluorescent antibody test was weakly positive in the first serum examined and positive in $N$ the second serum, indicating a rise in the level of antibody. The results of these serological investiga- $\omega$ tions are shown in Table 1.

Other investigations included a mantoux test $\stackrel{\circ}{\circ}$

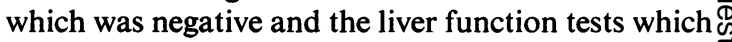
were normal. The sputum culture was sterile. The brucella abortus complement fixation, the cytome- -0 galovirus complement fixation and toxoplasma dye $\overrightarrow{\mathbb{D}}$ tests were also negative. No viruses were isolated $\frac{\rho}{\mathrm{D}}$ from the throat swab and faeces. The IgG was 1650 응 


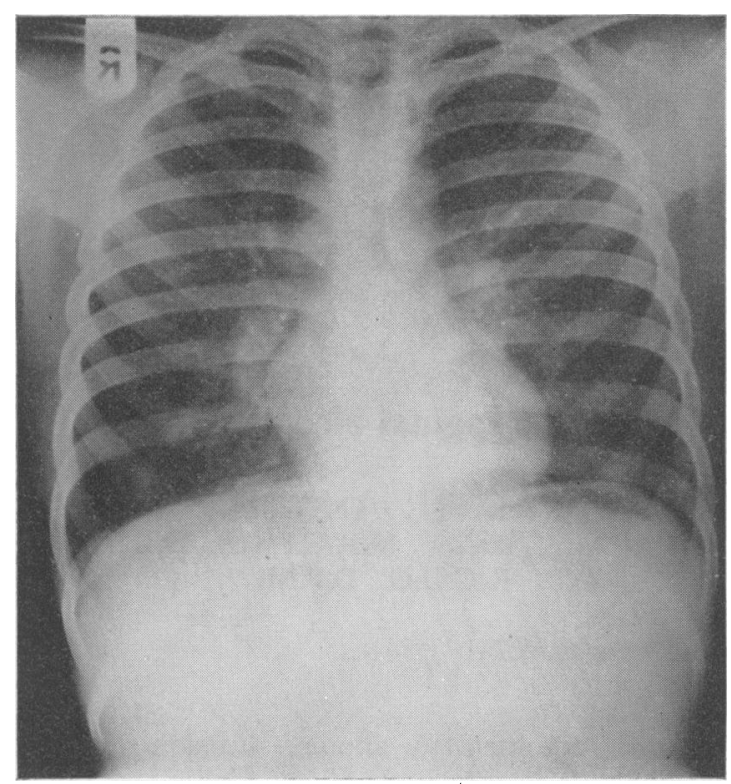

Fig. 2. Clearing of the lung fields 6 days later.

TABLe 1. Serological data

\begin{tabular}{|c|c|c|c|c|}
\hline Tests & Day 1 & Day 6 & Day 10 & 8 Weeks \\
\hline $\begin{array}{l}\text { Heterophil antibodies } \\
\text { (1) Unadsorbed } \\
\text { (2) GPK adsorption } \\
\text { (3) Ox Cell adsorption }\end{array}$ & $\begin{array}{l}* \\
* \\
*\end{array}$ & $\begin{array}{l}1 / 640 \\
1 / 640 \\
1 / 10\end{array}$ & $\begin{array}{l}* \\
* \\
*\end{array}$ & $\begin{array}{l}1 / 40 \\
1 / 40 \\
1 / 10\end{array}$ \\
\hline $\begin{array}{l}\text { Farmer's lung antibodies } \\
\text { (1) GD } \\
\text { (2) CFT }\end{array}$ & * & $\stackrel{+}{1 / 1280}$ & * & $\stackrel{+}{1 / 320}$ \\
\hline $\begin{array}{l}\text { Mycoplasma pneumoniae } \\
\text { CFT }\end{array}$ & $1 / 640$ & $1 / 2560$ & $1 / 1280$ & $1 / 320$ \\
\hline RSV CFT & $1 / 40$ & $1 / 160$ & * & $1 / 160$ \\
\hline $\begin{array}{l}\text { EB virus fluorescent } \\
\text { antibody test }\end{array}$ & $*$ & \pm & $*$ & + \\
\hline
\end{tabular}

*, not tested; +, positive; \pm , very weakly positive; GPK, guinea-pig kidney; GD, gel diffusion; CFT, complement fixation test.

$\mathrm{mg} / 100 \mathrm{ml}$, and $\operatorname{IgA} 450 \mathrm{mg} / 100 \mathrm{ml}$, and the IgM 135 $\mathrm{mg} / 100 \mathrm{ml}$.

The mother of the patient suffered from farmer's lung and had radiological features of the disease. She was also tested for farmer's lung antibodies; the gel diffusion test was positive and the complement fixation test showed a titre of $1 / 80$. The mycoplasma pneumoniae complement fixation test on the same serum was $1 / 320$ indicating a recent infection.

\section{Discussion}

The diagnosis of acute farmer's lung seemed likely in our case because of the history of exposure, rapid clinical response following removal from the antigen, and also a very high increase in the antibody titre and subsequent fall. Besides the mother of the patient also suffered from farmer's lung and had antibodies present to both farmer's lung and mycoplasma pneumoniae thus providing further epidemiological evidence. However, the finding of positive serological results may not necessarily imply clinical disease as shown by Pepys and Jenkins (1965) who found $18 \%$ of the farmers not suffering from farmer's lung had precipitating farmer's lung antibodies in their sera, although this was not the experience of Boyd (1971) in an epidemiological study in Scotland. The interest of this case is the positive serological findings to glandular fever, mycoplasma pneumoniae, RSV and EB virus.

Whether acute farmer's lung causes anamnestic reactions to other antigens or vice versa is uncertain, although in this case all antibody titres were very high initially falling subsequently to lower levels at 8 weeks. It has been suggested that the antigens of farmer's lung could produce damage to the bronchopulmonary tree in different ways (Spain and Van Wormer, 1965). Firstly they could act as allergens which initiate a sensitization process. Secondly they could predispose to other infections or they could cause a foreign body type of inflammation. A combination of one or all of these processes may be involved. It is nevertheless difficult to know whether exposure to the antigens of farmer's lung in this case resulted in multiple infections or whether these were coincidental. In the probable absence of a defect of immune response, it is suggested that these infections were not coincidental but occurred because severe exposure to farmer's lung antigens had damaged the pulmonary tree.

Although corticosteroid therapy is the usual treatment of farmer's lung especially if there is no response to withdrawal from the offending antigen (Hughes et al., 1969), it is interesting to note that this patient's acute episode resolved without the use of corticosteroids. In the light of our experience it might be preferable to withhold corticosteroids in farmer's lung until the possibility of concurrent infection by other agents has been excluded.

\section{Acknowledgments}

The authors are grateful to Professor O. P. Gray, Dr E. N. Thompson and Dr H. D. S. Morgan for their advice. Most of the serological investigations were made by the Public Health Laboratory, Carmarthen. Dr M. S. Pereira, Central Public Health Laboratory undertook the EB virus fluorescent antibody test.

\section{References}

Barrowcliff, D.F. \& Alabaster, P.G. (1968) Farmer's lung: a study of an early acute fatal case. Thorax, 23, 490. BoYD, D.H. (1971) The incidence of farmer's lung in Caithness. Scottish Medical Journal, 16, 261. 
Hughes, W.F., Mattimore, J.M. \& Arbesman, C.E. (1969) Farmer's lung in an adolescent boy. American Journal of Diseases in Childhood, 118, 777.

Pepys, J. \& Jenkins, P.A. (1965) Precipitin (FLH) test in farmer's lung. Thorax, 20, 21.
Rankin, J., Jaeschke, W.H., Callies, Q.C. \& Dickie, H.A. (1962) Farmer's lung. Annals of Internal Medicine, 57, 606.

SPAIN, D.M. \& VAN Wormer, D.E. (1965) Farmer's lung. Archives of Environmental Health, 10, 71.

\title{
Female genital self-mutilation as a cause of vaginal bleeding
}

\author{
M. A. SimpSON \\ M.B.B.S., L.R.C.P., M.R.C.S., D.P.M. \\ B. H. AnSTEE* \\ M.A., M.B., B.Chir., M.R.C.Psych., D.Obst., \\ R.C.O.G., D.P.M.
}

\begin{abstract}
Summary
While self-mutilation in the form of wrist and arm cutting is relatively common and genital self-mutilation in men is well recognized, female genital selfmutilation seems to be strikingly rare. With the exception of injuries secondary to frank self-induced abortion or the insertions of foreign bodies in children, only three cases of female genital self-mutilation have been reported in the literature so far. It is suggested that the phenomenon may not be as rare as hitherto supposed and therefore a further case is reported.
\end{abstract}

\section{Case report}

Mary D., 22, was born as the result of an unwanted and fiercely resented pregnancy. Her mother, who had regarded sex as abhorrent and unnecessary, became frigid from that time. She was an isolated, unhappy child who commonly feigned illness to avoid going to school. The day after starting work on leaving school, she began to complain of abdominal pain, inter-menstrual bleeding and heavy periods, and commenced a series of hospital admissions for investigation, including and appendicectomy at which the finding was 'mesenteric adenitis'. She made several attempts to start nursing training, but was not accepted. During this time she accepted her boyfriend's persistent persuasion and had sexual intercourse once. Subsequently she became frightened that she might be pregnant and introduced a knitting needle per vaginam producing some bleeding which resulted in a hospital admission and a dilatation and curettage which was followed by her first episode of wrist cutting, and the first or numerous admissions to psychiatric hospitals.

\footnotetext{
*Present address: The Old Manor Hospital, Salisbury, Wilts.
}

Later, admitted to another London teaching hospital for investigation of her abdominal symptoms, she began to behave in a more overtly disturbed fashion and it was suspected that her pyrexia, vomiting and other symptoms were self-induced. She tore open the wound from her lymphangiogram which became infected. While being seen as an out patient, she arrived at another teaching hospital's? casualty department having inflicted a deep laceration on her left breast and with a twig in her vagina which needed removal. She told the police she had been attacked in a car park, but withdrew her story before an identity parade was to be held. There followed a series of admissions to various hospitals with episodes of wrist cutting, swallowing metal objects and introducing small metal objects into her vagina. There were over a dozen separate incidents of self-mutilation responding poorly to a variety of treatments.

Then at the beginning of 1972 she was admitted to the local hospital following vaginal cuts producing sufficiently profuse bleeding to need transfusion. Two months later she arrived in our casualty department having lacerated her vulva and vagina with a knitting needle and a kitchen knife. The lacerations were repaired but on the gynaecology ward she smashed a window and cut her arm, and was transferred to a psychiatric ward. She had ten ECTs without much benefit and displayed a great deal of actingout behaviour including public and easily restrained attempts to mutilate herself. She inserted a sewing needle and on another occasion a knitting needle into her vagina. She told a nurse and then demanded to be allowed to discharge herself immediately. After the second such incident she was allowed to leave. 